\section{Fatores sociodemográficos e ocupacionais associados aos ganhos e perdas percebidos por trabalhadores de uma universidade pública frente à proximidade da aposentadoria}

\author{
Socio-demographic and occupational factors \\ associated with gains and losses perceived \\ by employees nearing retirement in a \\ public university
}

\author{
Factores sociodemográficos y ocupacionales \\ asociados a los beneficios y pérdidas percibidas \\ por trabajadores de una universidad pública \\ frente a la proximidad de la jubilación
}

Paloma de Souza Cavalcante Pissinati 1 Maria do Carmo Fernandez Lourenço Haddad 1 José Carlos Dalmas 1 Marcela Maria Birolim 1
Objetivou-se analisar os fatores sociodemográficos e ocupacionais associados aos ganhos e às perdas percebidos por trabalhadores de uma universidade pública frente à proximidade da aposentadoria. Pesquisa exploratória, transversal e quantitativa, realizada em uma universidade pública do norte do Estado do Paraná, Brasil, com 164 trabalhadores pré-aposentados, que responderam às escalas de importância de ganhos e de perdas da aposentadoria. Os dados foram analisados por regressão linear simples e múltipla a partir das dimensões das escalas, e foram usadas, como preditores, as variáveis sociodemográficas e ocupacionais. Os trabalhadores atribuíram maior importância aos ganhos do que às perdas da aposentadoria. O aumento da idade associou-se à menor valorização dos ganhos totais e do tempo para relacionamentos. O maior tempo de atuação contribuiu para a valorização das perdas totais e dos aspectos tangíveis do trabalho. Faz-se necessário criar espaços de reflexão nas instituições de trabalho que proporcionem a escuta das necessidades dos trabalhadores, sobretudo, daqueles com maior idade e tempo de serviço.

Envelhecimento; Aposentadoria; Saúde do Trabalhador 


\section{Introdução}

O envelhecimento tornou-se um fenômeno mundial influenciado, dentre outros fatores, pela diminuição das taxas de natalidade e mortalidade populacionais 1 . No Brasil, a proporção de pessoas com mais de 60 anos passou de $9 \%$, em 2001, para 12,1\%, em $2011^{2}$, e as projeções indicam que, em 2050, o país terá um contingente de 63 milhões de idosos 3

Nas universidades públicas, as repercussões do envelhecimento são ainda mais impactantes, pois decorrem do modelo histórico neoliberal, que se tornou evidente por volta de 1990, o qual implantou medidas como a restrição de verbas, que interferiu significativamente no processo de contratação de servidores 4 . Dessa forma, se a reposição regular dos trabalhadores tivesse sido mantida ao longo dos anos, atualmente, a proporção de indivíduos envelhecidos não seria tão expressiva em relação às demais faixas etárias.

Estudo realizado em uma universidade pública, na qual ocorreu esta pesquisa, identificou que 19,9\% dos trabalhadores encontravam-se em fase de pré-aposentadoria. Além disso, 73,9\% desses indivíduos poderiam solicitar a aposentadoria integral, dentre os quais, $10,6 \%$ possuíam entre 66 e 70 anos, resultados que revelam o envelhecimento da força de trabalho 5 .

Destaca-se que, ao envelhecerem, os trabalhadores vivenciam, de forma concomitante, outra mudança significativa em suas vidas, o desligamento laboral, que pode surpreender aqueles que não se prepararam para gerenciar as possíveis mudanças de hábitos. Dessa forma, além de adaptar-se ao envelhecimento, o indivíduo e o grupo com o qual convive também precisam se habituar à chegada da aposentadoria e aos impactos decorrentes desse novo processo ${ }^{6}$.

Ao se aproximar da aposentadoria, o trabalhador reconhece vantagens e desvantagens que influenciam sua tomada de decisão para o desligamento do trabalho. A adaptação à essa nova etapa de vida dependerá da capacidade de o indivíduo gerenciar os aspectos negativos e aprender com as mudanças vivenciadas no período de transição, de forma a ressaltar os pontos positivos 7 .

Dentre os ganhos experimentados com a aposentadoria, está a sensação de ter concluído uma etapa de vida e alcançar o descanso após anos de trabalho, como um processo natural e esperado em sua trajetória profissional. O indivíduo também pode perceber uma ampliação de seu papel social, por meio do desenvolvimento de atividades comunitárias, o que lhe confere a sensação de prazer ${ }^{8,9}$.

Contudo, muitos não conseguem imaginar suas vidas sem o trabalho, não aceitam que podem ser substituídos e acreditam que, ao se desligarem das atividades laborais, tornarãose improdutivos 10. Ainda, os trabalhadores podem manifestar insegurança quanto ao futuro financeiro e reconhecer perdas relacionadas ao sentimento de inutilidade, à ausência do status profissional e à diminuição das relações sociais 7,11 .

Portanto, a análise dos ganhos e das perdas constitui uma importante ferramenta para compreender os sentimentos dos indivíduos que se aproximam dessa etapa. Ainda, contribui para a implementação de ações favoráveis ao planejamento da aposentadoria em diferentes instituições e representa uma estratégia inovadora para pesquisas de enfermagem, que levará à reflexão sobre o papel do enfermeiro no atendimento das necessidades dessa população.

Diante disso, este estudo objetivou analisar os fatores sociodemográficos e ocupacionais associados aos ganhos e às perdas percebidos por trabalhadores de uma universidade pública frente à proximidade da aposentadoria.

\section{Método}

Trata-se de uma pesquisa transversal, exploratória, de abordagem quantitativa, realizada em uma universidade estadual pública localizada no norte do Estado do Paraná, Brasil. A instituição de estudo possuía, em 2014, aproximadamente, 1.312 trabalhadores que se encontravam em fase de pré-aposentadoria por idade ou por tempo de serviço, além daqueles que já poderiam estar aposentados.

Mediante identificação desses trabalhadores, foram aplicados os critérios de inclusão fundamentados na Lei Previdenciária no 8.213/1991, atualizada em julho de 2015 12, e na Emenda Constitucional no 41/2003 13 .

Instauraram-se, como critérios de exclusão, trabalhadores que se encontravam em período de férias e licenças durante a coleta de dados, além daqueles que não estavam no local de trabalho ou não retornavam aos contatos diretos, telefônicos, por intranet ou e-mail após três tentativas realizadas pela pesquisadora.

Após aplicação dos critérios de inclusão e exclusão, obteve-se uma população de 1.221 trabalhadores. Posteriormente, realizou-se o cálculo amostral, por meio de amostragem probabilística aleatória não estratificada, na qual os participantes são obtidos por técnica de sorteio, de forma a garantir iguais probabilidades de pertencerem ou não à amostra, resultando em uma amostra de 293 indivíduos. 
Entretanto, durante o período de coleta de dados que ocorreu entre os meses de novembro de 2014 e abril de 2015, o Estado do Paraná enfrentou uma situação de grave crise que também afetou o plano de previdência e aposentadoria dos servidores estaduais. Essa situação contribuiu para a deflagração de uma greve geral nas universidades estaduais que perdurou por quatro meses 14, incluindo a instituição de estudo, que trouxe impactos diretos aos trabalhadores em fase de pré-aposentadoria. Assim, em virtude da greve, a fim de evitar vieses nas respostas dos trabalhadores, tornou-se necessário encerrar a coleta de dados, obtendo uma amostra de 164 trabalhadores.

Para a coleta de dados, foram utilizados três instrumentos, o primeiro composto por dados sociodemográficos e ocupacionais do trabalhador, como sexo, idade, situação conjugal, remuneração, tempo de trabalho na instituição, entre outros.

O segundo, denominado Escala de Importância dos Ganhos Percebidos na Aposentadoria (EPGR), foi construído e validado no Brasil por França \& Vaughan 15 e objetiva medir a importância dos ganhos que os trabalhadores percebem que terão com a aposentadoria. Composta por 19 itens, agrupados em cinco dimensões: liberdade para o trabalho, ter mais tempo para relacionamentos, novo começo, ter mais tempo para as atividades culturais e de lazer e ter mais tempo para realizar investimentos.

O terceiro instrumento, Escala de Importância das Perdas Percebidas na Aposentadoria (EPLR), também construído e validado no Brasil por França \& Vaughan 15, visa medir a importância das perdas ou desvantagens que os trabalhadores poderão experimentar na aposentadoria. Também composta por 19 itens, avaliados em quatro dimensões: aspectos emocionais do trabalho, perda dos aspectos tangíveis do trabalho, perda dos relacionamentos no trabalho, perdas de salários e benefícios.

As escalas EPGR e EPLR possuem pontuações de Likert de um a quatro, em que um representa a maior importância e quatro a menor importância 15. Porém, a fim de facilitar a compreensão, neste estudo, a pontuação foi invertida para o cálculo do escore, obtendo a seguinte distribuição: "nenhuma importância" equivalendo um ponto; "pouca importância" dois pontos; "importante" três pontos; e "muito importante" quatro pontos. Assim como proposto pelos autores dos instrumentos 15 , o escore total das respostas dos participantes foi calculado a partir do somatório dos 19 itens de cada escala, mantendo-se a pontuação máxima de 76 pontos, com alteração apenas do grau de importância atribuído, sendo que quanto menor a importância menor a pontuação correspondente e quanto maior a importância maior o escore.

A análise dos dados foi realizada após a codificação das variáveis e dupla digitação no banco de dados do programa de análise estatística SPSS, versão 20.0 (IBM Corp., Armonk, Estados Unidos). Primeiramente, procedeu-se à análise descritiva dos dados mediante distribuição de frequências absolutas e relativas, medidas de tendência central (média) e de dispersão (desvio padrão) das variáveis sociodemográficas e ocupacionais.

A fim de analisar a associação entre os fatores sociodemográficos e ocupacionais e a percepção de ganhos e perdas da aposentadoria, adotou-se o modelo de regressão linear simples e, posteriormente, o modelo de regressão linear múltipla. As variáveis com valor de $\mathrm{p}<0,20$ foram incluídas no modelo de regressão linear múltipla e mantidas aquelas que apresentaram associação significativa $(\mathrm{p}<0,05)$. Incluíram-se as variáveis idade e sexo em todos os modelos, independentemente da significância estatística, devido à importância desses fatores na percepção de ganhos e perdas da aposentadoria. Foram considerados um nível de significância de $5 \%(\mathrm{p}<0,05)$ e um intervalo de $95 \%$ de confiança (IC95\%) em todos os testes.

O estudo foi realizado de forma a garantir o cumprimento dos preceitos da Resolução no 466/2012 16 (Certificado de Apresentação para Apreciação Ética - CAAE - no 3169114.5.0000.5231).

\section{Resultados}

Dos 164 trabalhadores, 122 (74,4\%) eram do sexo feminino, e 90 (54,9\%) viviam com parceiro. A média de idade foi de 58,4 anos, com desvio padrão de 4,5 anos, variando de 49 a 69 anos, sendo que 90 (54,9\%) possuíam entre 49 e 59 anos de idade.

A maioria, 67 (40,9\%), dos entrevistados informou possuir uma renda familiar entre quatro e 10 salários mínimos, e 97 (59,1\%) alegaram ter dependentes dessa renda. Quanto à escolaridade, $134(81,7 \%)$ estudaram até o nível de bacharelado ou pós-graduação, e 151 (92,1\%) relataram estar participando de algum curso de aperfeiçoamento profissional.

Os participantes foram classificados em duas categorias profissionais: técnicos, composta por 109 (66,5\%) trabalhadores; e docentes, com 55 (33,5\%) indivíduos. Ressalta-se que os trabalhadores pertencentes à categoria técnica, incluíam aqueles que não desempenhavam atividades relacionadas à docência no momento da cole- 
ta de dados na instituição em estudo, tais como enfermeiros, técnicos de enfermagem, farmacêuticos, médicos, assistentes sociais, técnicos em multimídia, administradores, técnicos administrativos, auxiliares operacionais, contadores, costureiros, advogados e telefonistas.

O tempo médio de trabalho na instituição foi de 31 anos, com mínimo de oito e máximo de 48 anos, sendo que $110(67,1 \%)$ atuavam há 31 anos ou mais. Grande parte, 120 (73,2\%), não realizava horas extras, e 158 (96,3\%) não possuíam outro vínculo empregatício.

Obteve-se um escore total médio de 49,4 pontos para a escala de ganhos da aposentadoria, sendo que 147 (89,7\%) trabalhadores atribuíram maior importância à oportunidade de ter mais tempo para esportes e atividades culturais, e 142 (86,6\%), ao tempo que terão para viajar a lazer após a aposentadoria. Em contrapartida, o interesse em participar da política e o fato de não representar mais a empresa foram considerados de menor importância por 145 (88,5\%) e 143 (87,1\%) participantes, respectivamente.

Por meio de regressão linear simples, identificaram-se associações significativas entre a idade, situação conjugal, escolaridade, renda e categoria profissional, frente à percepção dos ganhos totais e das dimensões da EPGR.

Já as análises de regressão linear múltipla indicaram que os indivíduos mais velhos atribuíram menor importância aos ganhos totais $(\beta=-0,239 ; p=0,003)$, ao tempo que terão para os relacionamentos $(\beta=-0,185 ; p=0,013)$ e a um novo começo $(\beta=-0,224 ; \mathrm{p}=0,004)$ após a aposentadoria; enquanto aqueles que possuíam par- ceiro avaliaram com maior importância o tempo para os relacionamentos ( $\beta=0,360 ; \mathrm{p}=0,000)$.

Ainda, a maior escolaridade esteve positivamente relacionada ao reconhecimento dos ganhos da dimensão novo começo $(\beta=-0,185$; $\mathrm{p}=0,016$ ); já os participantes com maiores salários conferiam menor importância ao tempo para atividades culturais e de lazer $(\beta=-0,163$; $\mathrm{p}=0,041)$ e para realizar investimentos $(\beta=$ 0,$254 ; p=0,010$ ). A dimensão liberdade para o trabalho não sofreu influência de nenhuma variável sociodemográfica ou ocupacional, como exposto na Tabela 1.

Quanto às perdas da aposentadoria, identificou-se um escore total médio de 43,6 pontos. Dentre as principais desvantagens, $144(87,8 \%)$ trabalhadores atribuíram maior importância ao relacionamento com colegas de trabalho e 140 $(85,4 \%)$ ao relacionamento com a equipe. Ainda, 154 (93,9\%) perceberam com menor importância o fato de não ter mais uma secretária, seguidos por $136(82,9 \%)$ que se referiram ao senso de ter um trabalho competitivo e a oportunidade de viajar a trabalho como perdas menos importantes.

A análise por regressão linear simples revelou associações significativas entre as variáveis escolaridade, renda, situação conjugal, tempo de trabalho e categoria profissional às dimensões da EPLR e à percepção geral de perdas da aposentadoria.

Após a regressão linear múltipla, identificouse que o aumento do tempo de trabalho influenciou os indivíduos a reconhecerem com maior importância as perdas totais $(\beta=0,174 ; p=0,040)$ e aquelas relacionadas aos aspectos tangíveis

Tabela 1

Fatores sociodemográficos e ocupacionais associados aos ganhos percebidos por trabalhadores de uma universidade pública frente à proximidade da aposentadoria, segundo análise de regressão linear múltipla. Paraná, Brasil, 2015 ( $n=164$ ).

\begin{tabular}{|c|c|c|c|}
\hline Dimensões EPGR & Fatores sociodemográficos e ocupacionais & $\beta$ & IC95\% \\
\hline Liberdade do trabalho & - & - & - \\
\hline Ter mais tempo para os & Aumento da idade * & $-0,185$ & $-0,242 ;-0,029$ \\
\hline relacionamentos & Possuir parceiro & 0,360 & 1,$412 ; 3,374$ \\
\hline \multirow[t]{2}{*}{ Novo começo } & Aumento da idade * & $-0,224$ & $-0,193 ;-0,037$ \\
\hline & Escolaridade bacharelado/pós-graduação & 0,185 & 0,$208 ; 2,016$ \\
\hline $\begin{array}{l}\text { Ter mais tempo para atividades } \\
\text { culturais e de lazer }\end{array}$ & Renda de 11 e mais salários mínimos & $-0,163$ & $-1,242 ;-0,025$ \\
\hline $\begin{array}{l}\text { Ter mais tempo para realizar } \\
\text { investimentos }\end{array}$ & Renda de 11 e mais salários mínimos & $-0,254$ & $-0,879 ;-0,123$ \\
\hline Ganhos totais & Aumento da idade * & $-0,224$ & $-0,712 ;-0,122$ \\
\hline
\end{tabular}

ß: Beta padronizado; EPGR: Escala de Importância dos Ganhos Percebidos na Aposentadoria; IC95\%: intervalo de 95\% de confiança.

*Variável contínua. 
do trabalho $(\beta=0,200 ; p=0,019)$. Ser docente contribuiu para que os trabalhadores atribuíssem maior importância às perdas relacionadas aos aspectos emocionais do trabalho $(\beta=0,257$; $\mathrm{p}=0,022)$ e aos salários e benefícios $(\beta=0,217$; $\mathrm{p}=0,045$ ); enquanto os indivíduos que recebiam maiores salários avaliaram a perda dos relacionamentos no trabalho com menor importância ( $\beta=-0,194 ; p=0,047)$, como mostra a Tabela 2 .

Destaca-se que as variáveis mais fortemente associadas ao reconhecimento das dimensões de ganhos da aposentadoria foram a situação conjugal e a idade. Enquanto as dimensões de perdas foram influenciadas, sobretudo, pelo tempo de trabalho na instituição e a categoria profissional.

\section{Discussão}

O predomínio de mulheres reforça o aumento da concentração de trabalhadoras do sexo feminino em instituições universitárias, as quais ocupam diversos cargos, dentre eles, a docência e a administração pública 17. Dessa forma, trata-se de um gênero economicamente ativo, cada vez mais presente no mercado profissional e que, muitas vezes, assume a função de líder no sustento familiar 18,19.

Ainda, a média de idade de 54,8 anos, o fato de possuírem dependentes da renda familiar e estarem em algum tipo de relacionamento são características que se assemelham à atual estrutura das famílias brasileiras, nas quais os indivíduos pré-aposentados atuam como alicerces financeiros dos lares, sustentando seus descendentes, além de grande parte possuir cônjuge 20 .

A maior escolaridade, identificada no estudo, constitui um fator de proteção para adaptação do trabalhador à aposentadoria 21. Entretanto, muitos referiram não estarem envolvidos em cursos de aperfeiçoamento, o que pode interferir negativamente, visto que a realização de atividades educacionais influencia o bem-estar do indivíduo após o desligamento do trabalho 22 .

Além disso, grande parte pertencia à carreira técnica, não possuía outro emprego, não realizava horas extras e trabalhava há muitos anos na instituição. Essa dedicação à empresa e à carreira profissional leva à reflexão sobre os possíveis impactos decorrentes do afastamento do trabalho e a capacidade dos participantes de se envolverem comnovasatividades, fatoresquepodem determinar a forma como vivenciarão a aposentadoria 7 .

Em geral, os trabalhadores atribuíram maior importância aos ganhos do que às perdas da aposentadoria. Segundo a teoria do comportamento planejado, quanto mais consequências positivas os indivíduos reconhecerem em relação a um comportamento, maiores as chances de praticálo 23 , o que pode contribuir para que o desligamento ocorra de forma assertiva nesse grupo.

Quanto aos ganhos da aposentadoria, os trabalhadores avaliaram com maior importância o tempo que terão para esportes e atividades culturais. Tais interesses contribuem positivamente para a qualidade de vida e favorecem o envolvimento dos participantes com outras ocupações após o desligamento laboral 22.

Contudo, os trabalhadores atribuíram menor importância à participação na política, resultado que se assemelha a outro estudo, no qual os trabalhadores consideraram essa vantagem como a segunda menos importante 8 . Ainda, também forneceram pouca importância ao fato de deixar de representar a empresa, o que indica que o trabalho e a instituição ocupam um grande espaço

Tabela 2

Fatores sociodemográficos e ocupacionais associados às perdas percebidas por trabalhadores de uma universidade pública frente à proximidade da aposentadoria, segundo análise de regressão linear múltipla. Paraná, Brasil, 2015 (n=164).

\begin{tabular}{|c|c|c|c|}
\hline Dimensões EPLR & Fatores sociodemográficos e ocupacionais & $\boldsymbol{\beta}$ & IC95\% \\
\hline Aspectos emocionais do trabalho & Categoria profissional docente & 0,257 & 0,$408 ; 5,092$ \\
\hline $\begin{array}{l}\text { Perda dos aspectos tangíveis do } \\
\text { trabalho }\end{array}$ & Aumento do tempo de trabalho * & 0,200 & 0,$020 ; 0,220$ \\
\hline $\begin{array}{l}\text { Perda dos relacionamentos no } \\
\text { trabalho }\end{array}$ & Renda de 11 e mais salários mínimos & $-0,194$ & $-1,142 ;-0,009$ \\
\hline Perda de salários e benefícios & Categoria profissional docente & 0,217 & 0,$018 ; 1,558$ \\
\hline Perdas totais & Aumento do tempo de trabalho * & 0,174 & 0,$011 ; 0,479$ \\
\hline
\end{tabular}

ß: Beta padronizado; EPLR: Escala de Importância das Perdas Percebidas na Aposentadoria; IC95\%: intervalo de $95 \%$ de confiança.

* Variável contínua. 
na vida dos participantes e remetem à importância de os programas de preparação estimularem o trabalhador a buscar novas atividades para ocupar o tempo livre, além do vínculo laboral 24.

$\mathrm{O}$ aumento da idade esteve associado a um menor reconhecimento dos ganhos totais e das dimensões de tempo para os relacionamentos e o novo começo. Destaca-se que, à medida que os indivíduos envelhecem, há uma maior dificuldade em refletir sobre a aposentadoria, aceitála como um processo natural em suas vidas e iniciarem atividades que favoreçam a reinserção profissional 21, fatores que podem contribuir para a menor valorização desses ganhos.

Por outro lado, os participantes que possuíam parceiro conferiram maior importância à dimensão tempo para relacionamentos. $\mathrm{O}$ interesse em investir nas relações interpessoais, sobretudo, nas familiares depende da satisfação gerada por essa convivência, assim, quanto mais benéfica maior será o interesse do trabalhador em dedicar-se a essas relações após a aposentadoria 7 .

Os trabalhadores com maior nível de escolaridade avaliaram a dimensão novo começo com grande importância. Esse resultado pode estar relacionado ao fato de que indivíduos com mais anos de estudo têm acesso à informação e se tornem favoráveis a se envolverem com novas atividades não relacionadas ao trabalho, além de apresentarem menores incertezas e ansiedades em relação às formas de desfrutarem da aposentadoria 18,21 .

A renda elevada associou-se à atribuição de menor importância para as dimensões de tempo para atividades culturais e de lazer, bem como para realizar investimentos, postura que pode estar relacionada ao fato de que, possivelmente, esses indivíduos já tenham acesso e realizem tais atividades. Contrariando essa informação, observou-se resultado de pesquisa que demonstrou que o investimento em atividades de lazer está relacionado às melhores condições financeiras, uma vez que esses indivíduos tendem a apresentar maior interesse em praticá-las de forma mais intensa após o desligamento laboral 7.

As principais perdas percebidas pelos trabalhadores foram os relacionamentos com colegas e equipe de trabalho, semelhante à pesquisa realizada com executivos brasileiros e neozelandeses 15 . Ao se aproximarem da aposentadoria, os indivíduos temem o rompimento dos vínculos estabelecidos no trabalho e, consequentemente, a redução da interação social 7,8.

A concretização da aposentadoria é influenciada pelo julgamento que o grupo de relações possui sobre essa tomada de decisão, sendo que, quanto mais indivíduos se relacionarem com o pré-aposentado, maior a necessidade de aprovação 25 . Ainda, faz-se necessário considerar que os relacionamentos interpessoais estabelecidos no ambiente laboral são construídos a partir de um contexto social que pode colaborar para que os indivíduos manifestem determinadas atitudes frente à aposentadoria e, portanto, necessitam ser analisados em toda a sua subjetividade.

Em contrapartida, atribuíram menor importância ao fato de não possuir mais uma secretária, deixar de ter competições laborais e de realizar viagens a trabalho. Infere-se que, possivelmente, essas questões não estavam presentes na prática dos trabalhadores, além de indicar que tais aspectos não serão fortemente percebidos ao se aposentarem.

A maior valorização das desvantagens gerais e daquelas relacionadas aos aspectos tangíveis do trabalho esteve associada ao aumento do tempo de serviço na instituição de estudo. Esse resultado reforça a necessidade de estimulá-los a buscarem outras fontes de prazer além do trabalho, o que contribuirá para o desligamento e para a criação de sua própria identidade após a aposentadoria 9 .

Identificou-se uma associação significativa entre pertencer à categoria docente e atribuir maior importância às perdas dos aspectos emocionais do trabalho e dos salários e benefícios. A interação com alunos e colegas de trabalho fornece prazer aos docentes, que podem sentir falta desses aspectos após o desligamento. Ainda, apesar de ser fonte de insatisfação para muitos 26 , a diminuição da remuneração também representa uma preocupação para os pré-aposentados 8 .

Já os indivíduos que recebiam maiores salários avaliaram a perda dos relacionamentos no trabalho com menor importância. Esse resultado pode estar associado ao fato de que melhores condições financeiras permitem aos trabalhadores usufruírem de uma vida social mais intensa e formar novas relações após a aposentadoria 8 , com isso, a diminuição dos vínculos laborais não seria fortemente percebida.

Diante disso, nota-se que os fatores sociodemográficos e ocupacionais podem influenciar na percepção de ganhos e perdas da aposentadoria Portanto, o conhecimento do perfil desses trabalhadores tornou-se fundamental para compreender suas atitudes frente à aproximação dessa etapa da vida.

Segundo a teoria do comportamento planejado, quando um indivíduo é estimulado a pensar positivamente sobre a execução de um comportamento, ele tende a valorizar as vantagens resultantes daquela ação, mas ao instigá-lo a refletir sobre a não realização, ele imaginará efeitos contrários 23. Assim, o trabalhador deve ser incenti- 
vado a reconhecer os ganhos da aposentadoria, uma vez que, quanto mais favorável se sentir em relação a esse comportamento, maiores serão as chances de concretizá-lo de forma saudável.

\section{Considerações finais}

Os participantes estavam mais favoráveis em relação à aposentadoria, mas a pequena diferença de importância atribuída às perdas indica que ainda as valorizam. Portanto, faz-se necessário planejar estratégias de intervenção que contribuam para o reconhecimento das vantagens e as formas de gerenciar as desvantagens desse processo.

Destaca-se a importância de dar continuidade ao programa de preparação para aposentadoria na instituição em estudo, a fim de promover ações voltadas, sobretudo, ao enfrentamento das perdas dos relacionamentos de trabalho. Ainda, deve-se estimular a participação dos trabalhadores mais velhos e com maior tempo de serviço, para instigá-los a perceber as vantagens e planejar sua saída de forma saudável.

A reflexão sobre ganhos e perdas da aposentadoria representa uma importante ferramenta para identificar os aspectos que impulsionam os indivíduos a concretizarem seu desligamento laboral e aqueles que podem adiar essa tomada de decisão. Assim, contribui para o diagnóstico gerencial sobre as atitudes desses trabalhadores e subsidia a atuação dos enfermeiros, enquanto profissionais capacitados para direcionar as ações de planejamento da aposentadoria nas diversas instituições de trabalho.

Ressalta-se, como limitações, a ocorrência da greve geral na instituição de estudo com repercussões diretas sobre a percepção que os participantes possuíam quanto à aposentadoria. Em consequência, o tamanho da amostra não permite generalizações dos resultados, o que reforça a pertinência de novas pesquisas que ampliem a análise das vantagens e desvantagens percebidas nessa etapa de vida.

\section{Colaboradores}

P. S. C. Pissinati contribuiu com a concepção e desenho do estudo, aquisição e interpretação dos dados, revisão crítica e redação de todas as versões do artigo. M. C. F. L. Haddad contribuiu com a concepção e desenho do estudo, interpretação dos dados, revisão crítica, redação de todas as versões do artigo e aprovação final da versão a ser publicada. J. C. Dalmas e M. M. Birolim contribuíram com o desenho do estudo, interpretação dos dados e revisão crítica das versões do manuscrito.

\section{Agradecimentos}

À universidade em estudo pelo apoio para a realização da pesquisa. 


\section{Referências}

1. Silva JCO, Amante CG, Klaes LS, Todescat M, Lobo E. Envelhecimento da força de trabalho do governo federal: desafios para a educação superior pública. Revista Gestão Universitária na América Latina 2012; 5:196-216.

2. Faleiros VP. Envelhecimento no Brasil do século XXI: transições e desafios. Argumentum 2014; 6:621.

3. Ministério da Saúde. Brasil terá 63 milhões de idosos em 2050. http://portal.saude.gov.br/portal/ saude/visualizar_texto.cfm?idtxt=34054\&janela $=1$ (acessado em 27/Ago/2015).

4. Granzotto TM. A implementação de ações neoliberais nas universidades públicas. Serviço Social \& Saúde 2011; 10:171-96.

5. Gvozd R, Haddad MCL, Garcia AB, Sentone ADD. Perfil ocupacional de trabalhadores de instituição universitária pública em pré-aposentadoria. Ciênc Cuid Saúde 2014; 13:43-8.

6. Sant'Ana Junior AL, Brêtas ACP. Aging of the military who served in the Brazilian army. Acta Paul Enferm 2011; 24:500-6.

7. Zanelli JC. Processos psicossociais, bem-estar e estresse na aposentadoria. Rev Psicol Organ Trab 2012; 12:329-40.

8. Carvalho CLS, Costa ISA, Pimenta RC. A percepção de servidores públicos sobre o momento de aproximação da aposentadoria: o caso do PRODERJ. Reuna 2013; 18:21-40.

9. Alvarenga LN, Kiyan L, Bitencourt B, Wanderley KS. The impact of retirement on the quality of life of the elderly. Rev Esc Enferm USP 2009; 43: 796-802.

10. Cuello MA, Concha LS. Preparación para la jubilación en los servicios públicos de Chile. Rev Chil Ter Ocup 2011; 11:1-16.

11. Vituoso Júnior JS, Tribess S, Paulo TRS, Martins CA, Romo-Perez V. Physical activity as an indicator of predictive functional disability in elderly. Rev Latinoam Enferm 2012; 20:259-65.

12. Brasil. Lei no 8.213 , de 24 de julho de 1991, atualizada em julho de 2015. Dispõe sobre os planos de benefícios da Previdência Social e dá outras providências. Diário Oficial da União 2015; 14 ago.

13. Brasil. Emenda Constitucional no 41, de 19 de dezembro de 2003. Modifica os arts. 37, 40, 42, 48, 96 , 149 e 201 da Constituição Federal, revoga o inciso IX do $§ 3$ do art. 142 da Constituição Federal e dispositivos da Emenda Constitucional no 20, de 15 de dezembro de 1998, e dá outras providências. Diário Oficial da União 2003; 31 dez.
14. Professores de universidades estaduais do Paraná entram em greve. G1 Paraná 2015; 10 fev. http:// gl.globo.com/pr/parana/noticia/2015/02/profes sores-de-universidades-estaduais-do-pr-entram -em-greve.html (acessado em 27/Ago/2015).

15. França LHFP, Vaughan G. Ganhos e perdas: atitudes dos executivos brasileiros e neozelandeses frente à aposentadoria. Psicol Estud 2008; 13: 207-16.

16. Conselho Nacional de Saúde. Resolução no 466, de 12 de dezembro de 2012. Dispõe sobre diretrizes e normas regulamentadoras de pesquisas envolvendo seres humanos. Diário Oficial da União 2012; 13 jun.

17. Teixeira ABM, Freitas MA. Mulheres na docência do ensino superior em cursos de física. Ensino em Re-Vista 2014; 21:329-40.

18. Bloom DE, Chatterji S, Kowal P, Lloyd-Sherlock P, McKee M, Rechel B, et al. Macroeconomic implications of population ageing and selected policy responses. Lancet 2015; 388:649-57.

19. Kuchemann BE. Envelhecimento populacional, cuidado e cidadania: velhos dilemas e novos desafios. Sociedade e Estado 2012; 27:165-80.

20. Rabelo DF, Neri AN. Tipos de configuração familiar e condições de saúde física e psicológica em idosos. Cad Saúde Pública 2015; 31:874-84.

21. Canizares JCL, Jacob Filho W. Fatores de risco à senilidade na transição à aposentadoria. Rev Bras Geriatr Gerontol 2011; 14:425-32.

22. Bressan MALC, Mafra SCT, França LHFP, Melo MSS, Loretto MDS. Bem-estar na aposentadoria: o que isto significa para os servidores públicos federais? Rev Bras Geriatr Gerontol 2013; 16:259-72.

23. Ajzen I, Sheikh S. Action versus inaction: antecipated affect in the theory of planned behavior. J Appl Soc Psychol 2013; 43:155-62.

24. Bressan MALC, Mafra SCT, França LHFP, Melo MSS, Loretto MDS. Trabalho versus aposentadoria: desvendando sentidos e significados. Oikos: Revista Brasileira de Economia Doméstica 2012; 23:226-50.

25. Ajzen I. Constructing a TpB questionare: conceptual and methodological considerations. http:// people.umass.edu/aizen/pdf/tpb.measurement. pdf (acessado em 27/Ago/2015).

26. Gonçalves ASR, Pires DEP. O trabalho de docentes universitários da saúde: situações geradoras de prazer e sofrimento. Rev Enferm UERJ 2015; 23:266-71. 


\section{Abstract}

The aim was to analyze socio-demographic and occupational factors associated with gains and losses perceived by employees nearing retirement in a public university. In an exploratory, cross-sectional, and quantitative survey, employees $(n=164)$ approaching retirement in a public university in northern Parana State, Brazil, assigned scales of importance to gains and losses. The data were analyzed with simple and multiple linear regression, based on the sizes of the scales, with socio-demographic and occupational variables as predictors. Employees assigned greater importance to retirement gains than losses. Increasing age was associated with less appreciation for total gains and time for relationships. Longer time on the job contributed to appreciation of total losses and tangible aspects of work. It is necessary to create spaces for reflection in employer institutions that promote listening to workers' needs, especially for older employees with longer time on the job.

Aging; Retirement; Occupational Health

\section{Resumen}

Se tuvo como objetivo analizar los factores sociodemográficos y ocupacionales, asociados a los beneficios y pérdidas percibidas por trabajadores de una universidad pública, frente a la proximidad de la jubilación. Se trata de una investigación exploratoria, transversal y cuantitativa, realizada en una universidad pública del norte del estado de Paraná, Brasil, con 164 trabajadores prejubilados, que respondieron a las escalas de importancia de beneficios y pérdidas de la jubilación. Los datos fueron analizados por regresión lineal simple y múltiple, a partir de las dimensiones de las escalas y como predictores las variables sociodemográficas y ocupacionales. Los trabajadores atribuyeron mayor importancia a los beneficios frente a las pérdidas de la jubilación. El aumento de la edad se asoció a una menor valorización de los beneficios totales y el tiempo para relaciones. El mayor tiempo de actuación contribuyó a una valorización de las pérdidas totales y de los aspectos tangibles del trabajo. Es necesario crear espacios de reflexión en las instituciones de trabajo, que proporcionen receptividad para escuchar las necesidades de los trabajadores, sobre todo, las de aquellos con mayor edad y tiempo de servicio.

Envejecimiento; Jubilación; Salud Laboral

Recebido em 31/Ago/2015

Versão final reapresentada em 21/Dez/2015

Aprovado em 25/Fev/2015 